\title{
Enhanced Activity of Anti-oxidant Enzymes by Foliar Spray of Nanoscale Zinc Oxide under Drought Stress Conditions in Peanut (Arachis hypogaea L.)
}

\author{
P. Latha², P. Sudhakar ${ }^{1}$, T.N.V.K.V. Prasad ${ }^{2}$
}

10.18805/LR-4790

\begin{abstract}
Background: Zinc plays an important role in controlling both generations and also detoxifies free oxygen radicals that can damage membrane lipids and sulfhydryl groups. Zinc in particular has an action that prevents membrane damage induced by superoxide radicals that produce $\mathrm{NADPH}$ oxidase. The use of zinc oxide $(\mathrm{ZnO})$ nanoparticles in agriculture had a significant impact on crop growth regulation, improved quality and improved stress tolerance. Hence, the current study aimed to study the foliar spray effect of nanoscale zinc oxide $\left(25 \mathrm{~nm}\right.$ mean particle size) at different concentrations and chelated bulk zinc suphate $\left(\mathrm{ZnSO}_{4}\right)$ and $\mathrm{comparable}$ control (unsprayed) in peanut to investigate the oxidative stress induction and enhanced antioxidant enzyme activity (SOD, POD, CAT) under conditions of water stress.

Methods: The experimental design was a randomized block design with two water regimes as main treatments viz., well watered (WW) and water stress (WS) conditions, eight foliar sprays along with unsprayed treatment (control) as sub treatments and 3 replications. The eight foliar spray treatments, includes nanoscale ZnO concentrations @ 10, 20, 40, 50, 100, 300, 1000 ppm, chelated bulk ZnSO (EDTA based) @ $0.1 \%$ (recommended dose). The antioxidant enzyme activity (SOD, POD, CAT) under conditions of both WW and WS was determined in the lab using UV spectrophotometer.

Result: The results of pot culture experiment revealed that nanoscale $\mathrm{ZnO}$ at a concentration of $50 \mathrm{ppm}$ increased biomass and pod yield and promoted antioxidant enzyme activity under water stress and well watered conditions compared to chelated bulk $\mathrm{ZnSO}_{4}$. Nanoscale $\mathrm{ZnO}$ showed increased activity under lower concentrations and inhibitory activity at higher concentrations that highlights the need for careful use of these particles in agriculture.
\end{abstract}

Key words: Antioxidant enzymes, Drought stress, Nanoscale Zinc oxide, Peanut.

\section{INTRODUCTION}

Peanut (Arachis hypogaea L.) is an essential oil seed, confectionery, food and feed legume crop worldwide. Drought is one of the key environmental problems that hinder crop production and threatens global food security. Moisture stress causes many biochemical, molecular and physiological changes and reactions that affect various cellular and whole plant processes (Prasad et al., 2008). In the current context of global warming and climate change, improving peanut for drought is crucial to ensure high productivity. At the cellular level, one of the effects of salt stress is to hinder the cellular function due to excess production of reactive oxygen species (ROS) (Hasanuzzaman et al., 2012). To reduce ROS accumulation, plants produce antioxidant enzymes, such as superoxide dismutase (SOD) and glutathione peroxidase (GPX), keeping ROS lower than toxic limit (Gill et al., 2015).

Detoxification of excess ROS is achieved by antioxidant enzymes such as superoxide dismutase, catalase, peroxidase, ascorbate peroxidase, glutathione reductase and other related enzymes. Super oxide dismutase acts as the first line of defense and detoxifies the super oxide radicals to hydrogen peroxide, while Catalase suppresses hydrogen peroxide. Under limited water availability, the photosynthetic process in the plant is greatly reduced and
${ }^{1}$ Comptroller of Examinations, Acharya NG Ranga Agricultural University, Lam, Guntur-522 034, Andhra Pradesh, India.

${ }^{2}$ Regional Agricultural Research Station, Acharya NG Ranga Agricultural University, Tirupati-517 502, Andhra Pradesh, India.

Corresponding Author: P. Sudhakar, Comptroller of Examinations, Acharya NG Ranga Agricultural University, Lam, Guntur-522 034, Andhra Pradesh, India. Email: sudhakarpalagiri@gmail.com

How to cite this article: Latha, P., Sudhakar, P. and Prasad, T.N.V.K.V. (2022). Enhanced Activity of Anti-oxidant Enzymes by Foliar Spray of Nanoscale Zinc Oxide under Drought Stress Conditions in Peanut (Arachis hypogaea L.). Legume Research. DOI: $10.18805 / L R-4790$.

Submitted: 13-09-2021 Accepted: 04-01-2022 Online: 14-02-2022

the continuous accumulation of photo-reducing energy causes more electrochemical forces in the tissues, forming superoxide radicals and hydrogen peroxide (Hernandez et al., 2001).

Zinc is one of the key nutrients in boosting the groundnut yields. Zn deficiency induce higher ROS levels in plants (Cakmak, 2000) and increases SOD, peroxidise (POD) and catalase (CAT) activities (Yu et al., 1998). Yield losses in groundnut due to $\mathrm{Zn}$ deficiency have been reported to be $13.3 \%$ to $20 \%$ (Singh et al., 2004). 
Nanomaterials control the plant growth and development at multiple levels (Kwak et al., 2016). For example, the positive effect of nano-ZnO at low concentrations which is well documented in peanut (Prasad et al., 2012), mung bean (Mahajan et al., 2011) and tomato (Singh et al., 2016), suggest that nanoparticles generate tolerance to different abiotic stresses, viz., drought (Zaimenko et al., 2014), salinity (Almutairi, 2016) and low temperature stress (Hawrylak-Nowak et al., 2010). Mitigation of abiotic stress by nanoparticles was often associated with the increased activity of antioxidant enzymes (Sturikova et al., 2018).

Nanoparticles of less than $100 \mathrm{~nm}$ in size fall into the transition zone, producing both positive and negative biological effects on living cells (Nel et al., 2006). Studies related to the response of nanoscale zinc oxide particles on antioxidant enzyme activities in peanut due to drought stress are lacking. Therefore, the objective of the current study is to measure the levels of anti oxidant activity experienced by peanut crop under water deficit stress by the foliar application of nanoscale zinc oxide particles at different concentrations and to confirm the role of antioxidant enzymes in providing drought tolerance.

\section{MATERIALS AND METHODS}

The present study was carried at Department of Crop Physiology, Institute of Frontier Technology (IFT), Regional Agricultural Research Station (RARS), Acharya N G Ranga Agricultural University (ANGRAU), Tirupati andhra Pradesh (A.P.) during 2015-16. ZnO nano particles of size 15-30 nm from the Department of Nanotechnology, IFT, RARS, ANGRAU, Tirupati, A.P. were used in the study. Nano crystalline zinc oxide has been prepared using an oxalate decomposition process. The samples are characterized by transmission electron microscopy (HRTEM, JEOL 3010), scanning electron microscopy (SEM, FEI quanta 200) and energy dispersive analysis X-rays (EDA X FEI quanta 200) (Prasad et al., 2012).

Peanut seeds of variety Narayani received from the Department of Genetics and Plant Breeding, RARS, ANGRAU, Tirupati, A.P. The pots $(20 \mathrm{~cm} \times 40 \mathrm{~cm})$ were filled with equal quantity of soil and four seeds were sown per pot. Care was taken to use the same soil in all pots to reduce soil variability. The experimental design was a randomized block design with two water regimes as main treatments viz., well watered (WW) and water stress (WS) conditions, eight foliar sprays along with unsprayed treatment (control) as sub treatments and 3 replications. Water stress (WS) regime is imposed by withholding irrigation for 40 days i.e., from 40 to 80 days after sowing (DAS). The eight foliar spray treatments, includes nanoscale ZnO concentrations @ 10,

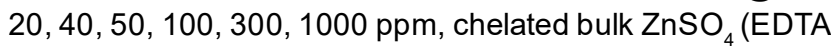
based)@0.1\% (recommended dose). The pots were maintained at field capacity (FC) until harvest under WW treatment, whereas under WS treatment, water stress was imposed @ 40\% FC during flowering when 50\% of the plants (at least two out of four plants) reached flowering. Foliar spray treatments were applied at 40 DAS and sampling was done after one week of foliar spray treatment.

SOD (EC 1.15.1.1) enzyme activity was estimated by its ability to inhibit photochemical reduction of Nitrobluete trazolium (NBT) method according to Madamanchi et al., 1994). In this assay, 1 unit of SOD is defined as the amount required to inhibit the photoreduction of NBT by $50 \%$ and SOD activity was measured spectrophotometrically at $560 \mathrm{~nm}$.

The activity of POD (EC 1.11.1.7) was measured by increased absorption of tetraguaiacol formation at $470 \mathrm{~nm}$ and the POD activity was measured as per extinction coefficient of its oxidation product, tetraguaiacol $\varepsilon=26.6$ $\mathrm{mM}^{-1} \mathrm{~cm}^{-1}$ (Castillo et al., 1984). Enzyme activity was estimated by monitoring the increase in absorption at 470 $\mathrm{nm}$ due to guaiacol oxidation.

CAT activity (EC 1.11.1.6) was determined by measuring the $\mathrm{H}_{2} \mathrm{O}_{2}$ disappearance (Aebi, 1984) in the reaction compound. The decrease in absorption at $240 \mathrm{~nm}$ on a UV spectrophotometer was observed for $1 \mathrm{~min}$. Enzyme activity was measured by calculating the amount of $\mathrm{H}_{2} \mathrm{O}_{2}$ decomposed.

At harvest, shoot dry weight (SDW) and pod yields were recorded after drying of individual plants and expressed in g plant $^{-1}$. The statistical analysis was assessed by Two Way Analysis of Variance (ANOVA) using GENSTAT software and the critical difference values were calculated at $5 \%$ significance level to compare the mean values.

\section{RESULTS AND DISCUSSION}

Of the newest technological innovations, nanotechnology offers an important opportunity and occupies a prominent position improving the existing crop management strategies and food production practices (Nair et al., 2010). The nano scale $\mathrm{ZnO}$ particles with mean diameter of $25 \mathrm{~nm}$ are crystalline as revealed by the high magnification image and the lattice of $\mathrm{ZnO}$ is clearly seen. Zhu et al., 2009 also reported lattice spacing of $0.26 \mathrm{~nm}$ to $0.28 \mathrm{~nm}$ of WURTZITE ZnO.

Application of nano-ZnO promoted melatonin synthesis and increased the antioxidant enzyme system, which reduces drought-induced damage to mitochondria and chloroplast in corn (Luying Sun et al., 2020). In the current study, water stress (WS) regime from 40 to 80 days after sowing (DAS) i.e., from pegging to pod formation stage, reduced soil moisture content by $42 \%$ at $0-5 \mathrm{~cm}$ soil depth and $40 \%$ at $15-30 \mathrm{~cm}$ soil depth compared to well watered (WW) plot where moisture level was maintained optimum throughout the crop growth period. Irrespective of the foliar treatments, the mean activity of SOD, POD and CAT increased significantly by $31.2 \%, 12.0$ and $28.0 \%$ respectively under WS compared to WW (Table 1). Kusvuran and Yildiz Dasgan (2017) in bean and Koushik Chakraborty et al. (2015) in peanut reported higher activity of antioxidant enzymes under moistures stress compared to control conditions. Under WS conditions, the activity of SOD, POD and CAT increased by $11 \%, 12 \%$ and $6.0 \%$ respectively in chelated $\mathrm{ZnSO}_{4} @ 1000$ ppm treatment compared to unsprayed control. SOD value increased 


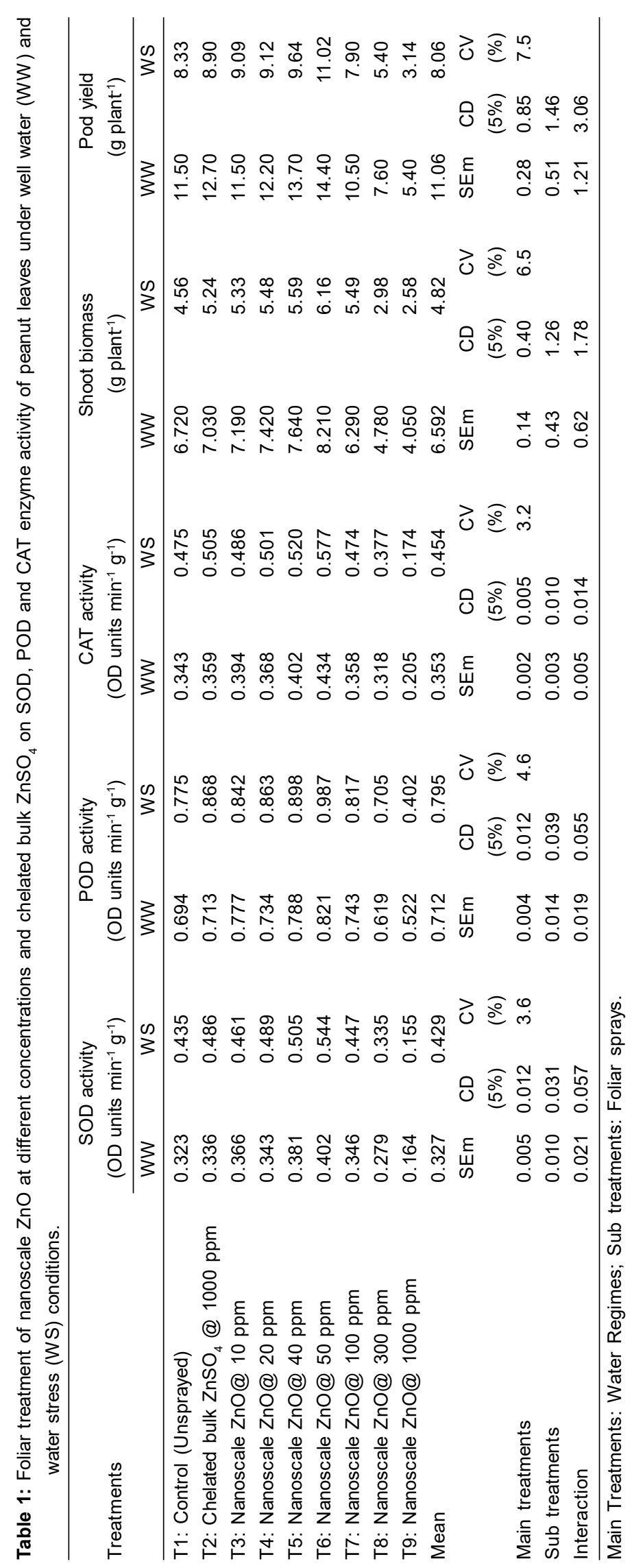


Enhanced Activity of Anti-oxidant Enzymes by Foliar Spray of Nanoscale Zinc Oxide under Drought Stress Conditions in...

significantly even with $\mathrm{ZnSO}_{4}$ spraying denotes the stimulating action of $\mathrm{Zn}$ as it is one of the cofactors of SOD (Cu/Zn SOD). Zinc may act as a scavenger of oxygen free radical production for mitigating the injury on biomembranes under salt stress and hence, treatment with zinc could reduce the effects of salinity stress in soybean plants and adequate zinc also prevents uptake and accumulation of $\mathrm{Na}$ in shoot, by increasing membrane integrity of root cells (Weria Weisany et al., 2012).

In the present study, among the different concentrations of nanoscale $\mathrm{ZnO}$, significantly highest SOD, POD and CAT activity recorded in nanoscale $\mathrm{ZnO} @ 50$ ppm treatment compared to unsprayed control and chelated bulk $\mathrm{ZnSO}_{4}$ under WW conditions. Similarly, foliar spray of nanoscale ZnO @ 50 ppm significantly recorded highest SOD, POD and CAT activity and increased by $25.1,27.4$ and $25.5 \%$ respectively compared to unsprayed control whereas SOD, POD and CAT activity increased by 11.9, 13.7 and $22.6 \%$ respectively compared to chelated bulk $\mathrm{ZnSO}_{4}$ respectively under WS conditions (Table 1; Fig 1). Drought results in accumulation of ROS, leading to lipid peroxidation of the cell membrane system, which is mainly due to the production of malondialdehyde. Luying et al. (2020), documented that, nano-ZnO significantly increased the activities of SOD, CAT and APX, which reduced the accumulation of $\mathrm{H}_{2} \mathrm{O}_{2}$ under drought and in agreement with this, the relative transcript abundance of Fe/Mn SOD, Cu/Zn SOD, APX and CAT in nano-ZnO plants was significantly up-regulated higher than that of non $\mathrm{ZnO}$ treatment plants under drought.

Biomass accumulation improved in the $\mathrm{ZnO}$ nanoparticle treated Chickpea seedlings and this response was associated with lower activity of prominent antioxidant enzymes, compared to control (Burman et al., 2013). The study by García-López et al. (2018) on the effects of suspensions of zinc oxide nanoparticles on germination of Capsicum chinense seeds resulted in increased activities of peroxidase and catalase. Vigna mungo seeds treated with different concentrations of $\mathrm{ZnO}$ nano particles showed significant induction of the activities of Glutathione reductase, Guaiacol peroxidase and Catalase activity (Pavani et al ., 2020).

Sharifi et al. (2012) reported that the tolerant wheat lines revealed high activity of POD and CAT enzyme under drought conditions with higher yields, thus showing positive correlation between enzyme activity and yield in drought conditions. Prasad et al., 2012 reported that, $\mathrm{ZnO}$ in the nanoscale form is absorbed by plants to a larger extent unlike bulk $\mathrm{ZnSO}_{4}$ and these particles proved effective in enhancing plant growth, development and yield.

The inherent small size and the associated large surface area of nanoscale $\mathrm{ZnO}$ fertilizer may increase the uptake of $\mathrm{Zn}$. All these factors may be responsible to give higher yields for nanoscale $\mathrm{ZnO}$ compared to chelated $\mathrm{ZnSO}_{4}$.

The present study reveals that, shoot biomass and pod yields recorded highest under WW compared to WS conditions. Shoot biomass and pod yields decreased by $37 \%$ under WS compared to WW conditions. Chelated $\mathrm{ZnSO}_{4}$
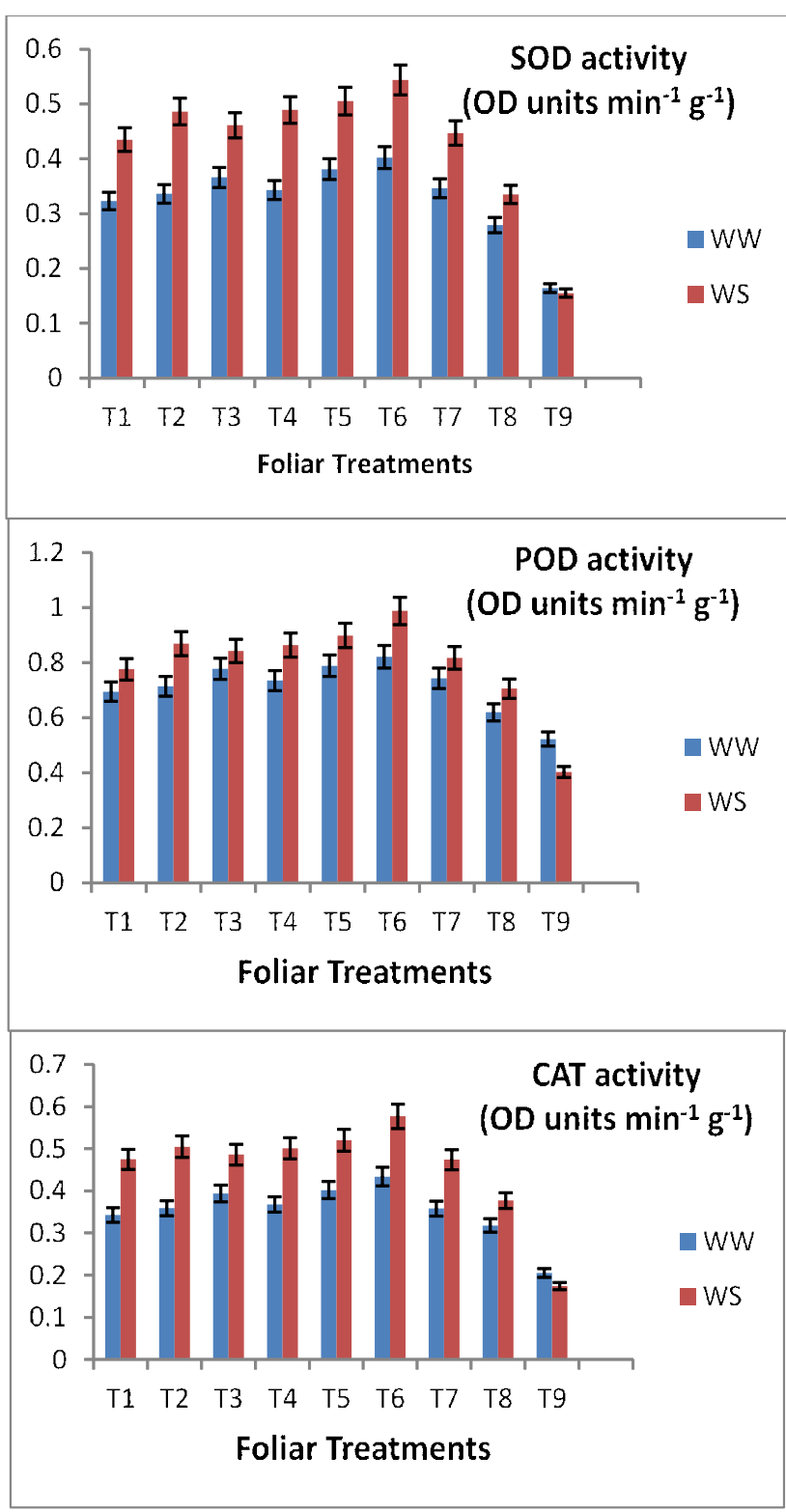

Fig 1: Anti oxidant enzyme activity by foliar spray of nanoscale zinc oxide under drought stress conditions in peanut.

T1: Unsprayed treatment (control), T2: chelated bulk $\mathrm{ZnSO}_{4}$ (EDTA based) @ 0.1\%, T3: Nanoscale ZnO @ 10 ppm, T4: Nanoscale ZnO@ 20 ppm, T5: Nanoscale ZnO@ 40 ppm, T6: Nanoscale ZnO, @ 50 ppm, T7: Nanoscale ZnO@ 100 ppm, T8: Nanoscale ZnO@ 300 ppm, T9: Nanoscale ZnO@1000 ppm.

foliar treatment recorded $5.0 \%$ increase in shoot biomass under both WW and WS conditions compared to unsprayed control whereas Chelated $\mathrm{ZnSO}_{4}$ foliar treatment recorded $10.0 \%$ and $7.0 \%$ enhanced pod yields under WW and WS conditions compared to unsprayed control (Table 1). Under various stressed conditions, optimum $\mathrm{Zn}$ concentrations enhanced the plant growth. The lower dry weight in the control treatments may be due to water limited stress as 
water limited stress have been known to severely reduce the growth of plants (Adrees et al., 2020). In the present study, significantly highest shoot biomass and pod yields were recorded at foliar spray treatment of nanoscale $\mathrm{ZnO}$ @ $50 \mathrm{ppm}$ compared to unsprayed control and chelated bulk $\mathrm{ZnSO}_{4}$ under WW conditions. Foliar spray of nanoscale $\mathrm{ZnO} @ 50$ ppm significantly recorded highest shoot biomass and pod yields and increased by 35.0 and $32.3 \%$ respectively compared to unsprayed control increased by 17.6 and $23.8 \%$ respectively compared to chelated bulk $\mathrm{ZnSO}_{4}$ under WS conditions (Table 1). Adrees et al. (2021) also reported that, the shoot, root and grain dry weights enhanced more under water deficit stress compared to normal water conditions where $100 \mathrm{mg} \mathrm{l}^{-1} \mathrm{ZnO}$ NPs were applied, over their respective control treatments.

The study by Hesham Alharby et al. (2016) reveals that, lower concentration of nanoscale $\mathrm{ZnO}$ was beneficial compared to the higher concentration of nanoscale $\mathrm{ZnO}$, at both salinity levels. The current study also observed that the nanoparticles at higher concentrations exhibit inhibitory effects on plants in terms of enzymatic activity and promontory activity at lower concentrations. At 1000 ppm, the antioxidant enzyme activity, shoot weight and pod yield significantly decreased compared to unsprayed control under both WW and WS conditions respectively in terms of plant growth showing phytotoxicity (Table 1).

\section{CONCLUSION}

Foliar application of chelated bulk $\mathrm{ZnSO}_{4}$ increased antioxidant enzyme activity, shoot biomass and pod yield compared to unsprayed control both under WW and WS conditions. Among different concentrations of nanoscale $\mathrm{ZnO}$, foliar treatment of nanoscale ZnO @ 50 ppm increased the activity of antioxidant enzymes, shoot biomass and pod yields both under WW and WS conditions compared to unsprayed control and chelated bulk $\mathrm{ZnSO}_{4}$. Nanoscale $\mathrm{ZnO}$ at higher concentrations showed inhibitory activity of antioxidants, shoot biomass and pod yield both under WW and WS conditions. The research is continuing for further exploitation of nano $\mathrm{ZnO}$ effects on other antioxidant enzymes in peanut.

\section{Conflict of interest: None.}

\section{REFERENCES}

Aebi, H. (1984). Catalase. Methods in Enzymology 105: 121-126. Adrees, M., Khan, Z.S., Ali, S., Hafeez, M., Khalid, S., Rehman, M.Z., Hussain, A., Hussain, K., Chatha, S.A.S. and Rizwan, M. (2020). Simultaneous mitigation of cadmium and drought stress in wheat by soil application of iron nanoparticles. Chemosphere. 238: 1-9.

Adrees, M., Khan, Z.S., Ali, S., Hafeez, M., Rizwan, M., Khalid, S., Hussain, K., Asrar, M., Alyemeni, M.N., Wijaya, L. and Ali, S. (2021). Foliar exposure of zinc oxide nanoparticles improved the growth of wheat (Triticum aestivum L.) and decreased cadmium concentration in grains under simultaneous $\mathrm{Cd}$ and water deficient stress. Ecotoxicology and Environmental Safety. 208: 111627.
Almutairi, Z.M. (2016). Effect of nano-silicon application on the expression of salt tolerance genes in germinating tomato (Solanum lycopersicum L.) seedlings under salt stress. Plant Omics. 9: 106-114.

Burman, U., Saini, M. and Kumar, P. (2013). Effect of zinc oxide nanoparticles on growth and antioxidant system of chickpea seedlings. Toxicological and Environmental Chemistry. 95(4): 605-612.

Cakmak, I. (2000). Role of zinc in protecting plant cells from reactive oxygen species. New Phytologist. 146:185-205.

Castillo, F. I., Penel, I. and Greppin, H. (1984). Peroxidase release induced by ozone in Sedum album leaves: Involvement of $\mathrm{Ca}^{2+}$. Plant Physiol. 74: 846-851. doi10.1104/pp.74.4.846

Gill, S.S., Anjum, N.A., Gill, R., Yadav, S., Hasanuzzaman, M., Fujita, M., Mishra, P., Sabat, S.C. and Tuteja, N. (2015). Superoxide dismutase-mentor of abiotic stress tolerance in crop plants. Environmental Science and Pollution Research. 22(14): 10375-94.

Hasanuzzaman, M., Hossain, M.A., da Silva, J.A.T. and Fujita, M. (2012). Plant Responses and Tolerance to Abiotic Oxidative Stress: Antioxidant Defense as a Key Factor. In: Crop Stress and its Management: Perspectives and Strategies. [Venkateshwarulu, B., Shanker, A.K., Shanker, C., Mandapaka, M. (eds)]. Springer, Berlin. pp. 261-315.

Hawrylak-Nowak, B., Matraszek, R. and Szymańska, M. (2010). Selenium modifies the effect of short-term chilling stress on cucumber plants. Biological Trace Element Research. 138: 307-315. doi: 10.1007/s12011-010-8613-5.

Hernández, J.A., Jiménez, A., Mullineaux, P.M. and Sevilla, F. (2001). Tolerance of pea (Pisum sativum L.) to long-term salt stress is associated with induction of antioxidant defenses. Plant Cell Environment. 23: 853-862.

Hesham, F. Alharby, Ehab, M.R. Metwali., Michael, P. Fuller. and Amal, Y. Aldhebiani. (2016). Impact of zinc oxide nanoparticle application on callus induction, plant regeneration, element content and antioxidant enzyme activity in tomato (Solanum lycopersicum mill.) under salt stress. Archives of Biological Sciences. 68(4): 723-735.

García-López, J. I., Ricardo Hugo Lira-Saldivar., Francisco ZavalaGarcía., Emilio Olivares-Sáenz., Guillermo Niño-Medina., Norma Angélica Ruiz-Torres., Bulmaro Méndez-Argüello. and Enrique Díaz-Barriga. (2018). Effects of zinc oxide nanoparticles on growth and antioxidant enzymes of Capsicum chinense. Toxicological and Environmental Chemistry. 100: 5-7

Pavani, K.V., Mallula Beulah. and Govinda Udayar Sai Poojitha. (2020). The Effect of Zinc Oxide Nanoparticles (ZnO NPs) on Vigna mungo L. Seedling Growth and Antioxidant Activity. Nanoscience and Nanotechnology-Asia. 10(2): 117-122.

Koushik Chakraborty., Amrit, L. Singh., Kuldeep, A. Kalariya., Nisha Goswami. and Pratap, V. Zala. (2015). Physiological responses of peanut (Arachis hypogaea L.) cultivars to water deficit stress: Status of oxidative stress and antioxidant enzyme activities. Acta Botanica Croatica. 74(1): 123-142.

Kusvuran, S. and Yildiz Dasgan, H. (2017). Effects of drought stress on physiological and biochemical changes in Phaseolus vulgaris L. Legume Research. 40: 55-62. 
Kwak, J.I. and An, Y.J. (2016). The current state of the art in research on engineered nanomaterials and terrestrial environments: Different-scale approaches. Environmental Research. 151: 368-382.

Luying, S., Fengbin, S., Junhong, G., Xiancan, Z., Shengqun, L., Fulai, L. and Xiangnan, L. (2020). Nano-ZnO-induced drought tolerance is associated with melatonin synthesis and metabolism in maize. International Journal of Molecular Sciences. 21(3): 782.

Madamanchi, N.R., Donahue, J.V., Cramer, C.L., Alscher, R.G. and Pedersen, K. (1994). Differential response of Cu, Zn superoxide dismutase in two pea cultivars during a short term exposure to sulphur dioxide. Plant Molecular Biology. 26: 95-103.

Mahajan, P., Dhoke, S. and Khanna, A. (2011). Effect of nano-ZnO particle suspension on growth of mung (Vigna radiata) and gram (Cicer arietinum) seedlings using plant agar method. Journal of Nanotechnology, Article ID: 696535. https://doi: 10.1155/2011/696535.

Nair, R., Varghese, S.H., Nair, B.G., Maekawa, T., Yoshida, Y. and Kumar, D.S. (2010). Nanoparticulate material delivery to plants. Plant Science. 179(3): 154-63.

Nel, A., Xia, T., Madler, L. and Li. N. (2006). Toxic potential of materials at the nanolevel. Science. 311: 622-627.

Prasad, T.N.V.K.V., Sudhakar, P., Sreenivasulu, Y., Latha, P., Munaswamy, V., Raja Reddy, K., Sreeprasad, T.S., Sajanlal, P.R. and Pradeep, T. (2012). Effect of nanoscale zinc oxide particles on the germination, growth and yield of peanut. Journal of Plant Nutrition. 35(6): 905-27.

Prasad, P.V. Vara, Staggenborg, S. and Ristic, Z. (2008). Impacts of drought and/or heat stress on physiological, developmental, growth and yield processes of crop plants. Advances in Agricultural Systems Modeling Series. 1. 301-355.
Sharifi, P., Amirnia, R., majidi, E., Hadi, H., Roustaii, M., Nakhoda, B., Alipoor, H. M. and Moradi, F. (2012). Relationship between drought stress and some antioxidant enzymes with cell membrane and chlorophyll stability in wheat lines. African Journal of Micro-biology Research. 6: 617623.

Singh, A., Singh, N., Hussain, I., Singh, H., Yadav, V. and Singh, S. (2016). Green synthesis of nano zinc oxide and evaluation of its impact on germination and metabolic activity of Solanum lycopersicum. Journal of Biotechnology. 233: 84-94.

Singh, A.L., Basu, M.S. and Singh, N.B. (2004). Mineral disorders of groundnut. National Research center for groundnut (ICAR), Junagadh India. pp. 85.

Sturikova H., Krystofova O., Huska D., Adam V. (2018). Zinc, zinc nanoparticles and plants. Journal of Hazardous Materials. 349: $101-110$.

Weria, W., Yousef, S., Gholamreza, H., Adel, S., Kazem, G.G. (2012). Changes in antioxidant enzymes activity and plant performance by salinity stress and zinc application in soybean (Glycine max L.). Plant Omics Journal. 5(2): 60-67.

Yu, Q., Osborne, L., Rengel, Z. (1998). Micronutrient deficiency changes activities of superoxide dismutase and ascorbate peroxidase in tobacco plants. J. Plant Nutr. 21(7): 14271437.

Zaimenko, N.V., Didyk N.P., Dzyuba, O.I., Zakrasov, O.V., Rositska, N.V. and Viter A.V. (2014). Enhancement of drought resistance in wheat and corn by nanoparticles of natural mineral analcite. Ecologia Balkanica. 6: 1-10.

Zhu, G., Xu, C., Yang, Y., Zheng, K. and Sun. X. (2009). Diskcapped multipod arrays of zinc oxide. Materials Chemistry and Physics. 113: 115-118. 